\title{
Body composition, adipokines, bone mineral density and bone remodeling markers in relation to IGF-1 levels in adults with Prader-Willi syndrome
}

\author{
I. Caroline van Nieuwpoort ${ }^{1 *}$ (D, Jos W. R. Twisk², Leopold M. G. Curfs ${ }^{3}$, Paul Lips ${ }^{1}$ and Madeleine L. Drent ${ }^{1}$
}

\begin{abstract}
Background: In patients with Prader-Willi syndrome (PWS) body composition is abnormal and alterations in appetite regulating factors, bone mineral density and insulin-like growth factor-1 (IGF-1) levels have been described. Studies in PWS adults are limited. In this study, we investigated body composition, appetite regulating peptides, bone mineral density and markers of bone remodeling in an adult PWS population. Furthermore, we investigated the association between these different parameters and IGF-1 levels because of the described similarities with growth hormone deficient patients.

Methods: In this cross-sectional observational cohort study in a university hospital setting we studied fifteen adult PWS patients. Anthropometric and metabolic parameters, IGF-1 levels, bone mineral density and bone metabolism were evaluated. The homeostasis model assessment of insulin resistance (HOMA2-IR) was calculated. Fourteen healthy siblings served as a control group for part of the measurements.

Results: In the adult PWS patients, height, fat free mass, IGF-1 and bone mineral content were significantly lower when compared to controls; body mass index (BMI), waist, waist-to-hip ratio and fat mass were higher. There was a high prevalence of osteopenia and osteoporosis in the PWS patients. Also, appetite regulating peptides and bone remodelling markers were aberrant when compared to reference values. Measurements of body composition were significantly correlated to appetite regulating peptides and high-sensitive C-reactive protein (hs-CRP), furthermore HOMA was correlated to BMI and adipokines.

Conclusion: In adults with Prader-Willi syndrome alterations in body composition, adipokines, hs-CRP and bone mineral density were demonstrated but these were not associated with IGF-1 levels. Further investigations are warranted to gain more insight into the exact pathophysiology and the role of these alterations in the metabolic and cardiovascular complications seen in PWS, so these complications can be prevented or treated as early as possible.
\end{abstract}

Keywords: PWS, IGF-1, Body composition, Appetite regulating peptides, Bone mineral density

\footnotetext{
* Correspondence: ic.vannieuwpoort@vumc.nl

${ }^{1}$ Department of Internal Medicine, Section Endocrinology, VU University

Medical Center and Amsterdam Neuroscience, De Boelelaan 1117, 1081 HV

Amsterdam, The Netherlands

Full list of author information is available at the end of the article
} 


\section{Background}

Prader-Willi syndrome (PWS), first described in 1956, is a genetic disorder caused by abnormalities on chromosome 15. Hypothalamic dysfunction is supposed to play a causal role in the characteristic clinical symptoms such as feeding difficulties, hypotonia, hyperphagia, morbid obesity, endocrine dysfunction, short stature, behavioral abnormalities, mental retardation, high pain threshold and alterations in temperature regulation [1-5]. Most patient with PWS are (morbidly) obese and their body composition (BC) is aberrant with a decreased muscle and lean body mass. Not only in obese but also in non-obese PWS patients fat mass is increased in comparison to subjects with simple obesity and a comparable body mass index (BMI) [6-12]. The abnormalities in body composition described in PWS are very comparable to those seen in patients with growth hormone deficiency (GHD).

Since hypothalamic dysfunction might be an important causal factor in PWS and hunger and satiety are regulated by the hypothalamus, a number of studies investigated concentrations of appetite regulating peptides in children and adults with PWS. The exact underlying mechanisms of the physiology of appetite regulating hormones or adipokines and their possible pathophysiological role in the development of obesity and metabolic and cardiovascular diseases are not yet fully understood, especially not in PWS patients. It is known that ghrelin, mainly secreted from the stomach, is an orexigenic peptide which stimulates food intake and is decreased in normal subjects after a meal [13]. Plasma ghrelin levels are elevated in PWS patients when compared to healthy or obese controls, possibly even at young age before the development of obesity $[5,14-20]$. Leptin is an appetite-suppressing peptide which also promotes energy expenditure and is secreted predominantly by adipose tissue $[13,21]$. Leptin levels are positively correlated to BMI and are known to be elevated in obese subjects, also known as "leptin resistance". After fasting or weight loss, leptin levels decrease. However, leptin was initially described as having a pro-inflammatory function [21]. Data on leptin concentrations in PWS patients are conflicting, showing normal or elevated levels [5, 22-27]. Adiponectin, secreted by adipocytes, is known to have anti-atherogenic and antiinflammatory effects and also has effects on lipid and glucose metabolism as it improves insulin sensitivity and glucose uptake $[5,13,21]$. Fasting adiponectin levels are reported to be higher in PWS subjects when compared to controls with simple obesity, but lower or normal when compared to lean control subjects [5, 11, 26, 28, 29]. Levels of resistin, secreted by macrophages and white adipose tissue, are elevated in human subjects with obesity. Although resistin causes insulin resistance in rodents, in humans it seems to have a more pro-inflammatory effect than a role in glucose homeostasis [21]. Studies on levels of resistin in PWS subject are scarce, but a significantly higher resistin concentration was reported in PWS patients in comparison with both healthy lean subjects and subjects with obesity [26].

Since PWS is characterized by obesity with a high fat percentage, one could expect an unfavorable glucose homeostasis and lipid profile with an increased risk for cardiovascular disease. However, data on metabolic profiles have been conflicting, with studies showing elevated plasma insulin levels indicating insulin resistance, but also normal or even increased insulin sensitivity in comparison to subjects with simple obesity has been reported $[10,12$, 30-33]. Lipid profile seems to be within the normal range or comparable to subjects with simple obesity $[11,12,23$, 31]. The concentration of high-sensitive C-reactive protein (hs-CRP), as a marker of low-grade systemic inflammation and known predictor of cardiovascular disease, is reported to be elevated in subjects with PWS [34-36]. Studies with regard to bone mineral density (BMD) in PWS patients show that BMD is decreased and markers of bone turnover are elevated [23, 37, 38].

The aim of the present study was to investigate body composition, appetite regulating peptides, BMD and markers of bone remodeling in an adult population of PWS patients. Healthy brothers and sisters of the PWS patients served as a control group for part of these measurements. Furthermore, we analyzed IGF-1 levels because of the described similarities of PWS patients with GHD patients. We hypothesized that that body composition, appetite regulating peptides, BMD and markers of bone remodeling are deviant in the PWS patients and expected to find an association with IGF-1 levels, at least for part of these parameters. We also investigated whether there was a gender difference within the PWS patients.

\section{Subjects and methods \\ Subjects}

Subjects for this study were recruited via the Dutch Prader-Willi patients' association, as described before [39]. In summary, we included fifteen PWS patients with genetically confirmed PWS, eleven females and four males, median age 22.0 years (range 19.2-42.9). Patients were excluded if they had received $\mathrm{GH}$-treatment within three months before enrolment. Written informed consent was obtained from the patients and their parents or caretakers. The study was approved by the Medical Ethics Review Committee of the VU University Medical Center and was conducted according to the principles of the Helsinki Declaration.

\section{Control group}

Fourteen healthy brothers and sisters of the included PWS patients constituted the control group, seven females and seven males, median age 28.5 years (range 17.5-41.3). They all had a good general health without a 
history of pituitary disease, surgery or radiotherapy of the head. IGF-1 levels were within the normal range for age and gender in all control subjects.

\section{Methods}

Medical history was taken in all PWS patients and subjects in the control group and a general physical examination was performed. In all participants, height (m), weight $(\mathrm{kg})$, waist and hip circumference $(\mathrm{cm})$ were measured and BMI $\left(\mathrm{kg} / \mathrm{m}^{2}\right)$ and waist-to-hip ratio (WHR) were calculated as described earlier [39].

\section{Genetic analysis}

In all patients, the diagnosis of PWS was genetically confirmed as described before at the Department of Clinical Genetics, Maastricht University Medical Center, The Netherlands [39].

\section{Laboratory tests}

Main laboratory tests were performed in PWS patients only. Blood samples were drawn at approximately 08:0010:00 am after an overnight fast. Standard laboratory tests were done to rule out any underlying disease and revealed no relevant abnormalities. Blood samples for hormonal assessments were drawn at the same time, but were analyzed altogether at the end of the study. In healthy controls only IGF-1 measurements were performed. IGF-1 and IGFBP-3 (insulin-like growth factor binding protein-3): Immunometric assay, Luminescence, Immulite $2500^{\circ}$ laboratory assay, Siemens Medical Solutions Diagnostics, USA. Reference range gender- and age-specific. Both IGF-1 concentration and IGF-1 standard deviation scores (SDS) were used in the analysis. 25-Hydroxy-vitamin D: Competitive binding protein assay, after extraction, Diasorin, Stillwater Minnesota, USA. Lower limit of quantitation: $5 \mathrm{nmol} / \mathrm{L}$. Mean intra-assay \% CV at level of $8 \mathrm{nmol} / \mathrm{L}$ is $12 \%$, at level of $25 \mathrm{nmol} / \mathrm{L}$ mean intra-assay \% CV is $9 \%$ and at level of $100 \mathrm{nmol} / \mathrm{L}$ mean intra-assay \% CV is $7 \%$. Reference values: $25-125 \mathrm{nmol} / \mathrm{L}$. Osteocalcin: Immunometric assay (colorimetric), BioSource, Nivelles, Belgium. Lower limit of quantitation: $0.4 \mathrm{nmol} / \mathrm{L}$. Mean intra-assay $\% \mathrm{CV}<5 \%$ at whole range. Reference values: $0.4-4.0 \mathrm{nmol} / \mathrm{L}$. Insulin: Immunometric assay, Luminescence, Advia Centaur, Siemens Medical Solutions Diagnostics, USA. Lower limit of quantitation: $10 \mathrm{pmol} / \mathrm{L}$. Mean intra-assay $\% \mathrm{CV}$ at level of $20 \mathrm{pmol} / \mathrm{L}$ is $4 \%$, at level of $500 \mathrm{pmol} / \mathrm{L}$ mean intra-assay $\% \mathrm{CV}$ is $3 \%$ and at level of $1500 \mathrm{pmol} / \mathrm{L}$ mean intra-assay $\% \mathrm{CV}$ is $4 \%$. Reference values (fasting): $12-96 \mathrm{pmol} / \mathrm{L}$. HsCRP: Immunometric assay (colorimetric), in-house with rabbit anti-CRP antibodies from DAKO. Lower limit of quantitation: $0.1 \mathrm{mg} / \mathrm{L}$. Mean intra-assay \% CV at level of $0.2 \mathrm{mg} / \mathrm{L}$ is $4 \%$, at level of $2 \mathrm{mg} / \mathrm{L}$ mean intra-assay \% CV is $5 \%$ and at level of $7 \mathrm{mg} / \mathrm{L}$ mean intra-assay \% CV is $6 \%$. Reference values: $<1.0$ low risk cardiovascular disease,
1.0-3.0 intermediate risk, $>3.0$ high risk. Adiponectin: Radioimmunoassay, Linco Research Inc., St. Charles Missouri USA. Lower limit of quantitation: $0.5 \mathrm{mg} / \mathrm{L}$. Mean intra-assay \% CV is $5 \%$ over the whole range. Reference values: $0.8-48 \mathrm{mg} / \mathrm{L}$. Ghrelin: Radioimmunoassay, Linco Research Inc., St. Charles Missouri, USA. Lower limit of quantitation: $240 \mathrm{ng} / \mathrm{L}$. Mean intra-assay \% CV is $4 \%$ over the whole range. Leptin: Radioimmunoassay, Linco Research Inc., St. Charles, Missouri, USA. Lower limit of quantitation: $0.5 \mu \mathrm{g} / \mathrm{L}$. Mean intra-assay \% CV at level of $5 \mu \mathrm{g} / \mathrm{L}$ is $8 \%$ and at level of $25 \mu \mathrm{g} / \mathrm{l}$ mean intra-assay \% CV is $3 \%$. Reference values for men (BMI 18-25) $2.5-8 \mu \mathrm{g} / \mathrm{L}$, women (BMI 18-25) 4.5-16 $\mu \mathrm{g} / \mathrm{L}$. Resistin: Immunometric assay (colorimetric), Biovendor Laboratory Medicine, INC, Modrice, Czech Republic. Lower limit of quantitation: $0.8 \mathrm{ng} / \mathrm{ml}$. Mean intra-assay \% CV is $5 \%$ over the whole range. Reference values: $4.1-12.1 \mathrm{ng} / \mathrm{ml}$. All other hormonal/laboratory assessments were performed at the endocrine laboratory of the VU University Medical Center with commercially available, regularly internal and external quality controlled immunoassays. The homeostasis model assessment of insulin resistance (HOMA2-IR) was calculated with fasting glucose and insulin levels by the HOMA2 calculator as provided by the website of the University of Oxford (http://www.dtu.ox.ac.uk/homacalculator).

\section{Urine analysis}

A fasting 2-h urine sample was used for measurements of creatinine, calcium and hydroxyproline in PWS patients. Reference values for creatinine: $5.3-17.7 \mathrm{mmol} /$ $24 \mathrm{~h}$, for calcium: $2.5-8.0 \mathrm{mmol} / 24 \mathrm{~h}$, for hydroxyproline: $<25 \mathrm{mmol} / \mathrm{mol}$ creatinine.

\section{Bioelectric impedance analysis (BIA)}

In both PWS patients and healthy controls body composition was measured by BIA using RJL 101/S/D; Akern-Rijl Systems. For BIA calculations, the method as described by Lukaski et al. [40] was used.

\section{Dual-energy X-ray absorptiometry (DXA)}

In PWS subjects only, body composition (BC) and bone mineral density (BMD) were measured using the Hologic QDR-4500. BMD was measured at the lumbar spine at the L1-L4 level and at the hip region (total hip).

\section{Statistical analysis}

All analyses were performed using the statistical software package SPSS version 21 (SPSS, Chicago, IL, USA). All data are presented as median with interquartile range (IQR) unless stated otherwise since most variables were not normally distributed. For comparison between patients and controls and between males and females the MannWhitney U test was used. Spearman's rank correlation test was used to analyze correlations between pairs of variables. 
A $p$-value of $<0.05$ was considered statistically significant and all test were two-tailed.

\section{Results}

Fifteen adult PWS patients were included in this study. Two subjects used a vitamin D supplement, two persons a multivitamin supplement. One subject was treated with a bisphosphonate. Four of the PWS patients were treated with $\mathrm{GH}$ in the past (treatment duration 712 years), but all stopped treatment at least 5 months before the study. Two of the patients suffered from hypothyroidism and were treated with thyroxin in a stable dose, one of the patients used hydrocortisone in a stable dose because of adrenal insufficiency. Only two of the fifteen patients $(13 \%)$ had normal gonadal function, as was published earlier [39]. Of the hypogonadal patients, 54\% was treated with sex steroids. None of the subjects received treatment for diabetes mellitus or was treated with statins. In three subjects, BMD of the lumbar spine could not be measured because of the presence of osteosynthesis material, furthermore one subject refused measurement of total body BMD.

Table 1 shows body composition characteristics of the PWS patients and controls, as well as measurements of bone mineral density in the PWS patients. In the whole group of PWS patients, height, IGF-1, fat free mass (FFM) and bone mineral content (BMC) measured by BIA were significantly lower when compared to controls; BMI, waist, WHR and fat mass (FM) were significantly higher. In the PWS subjects, T- and Z-scores of the of BMD of the lumbar spine and total hip were low. Two patients met the criteria for osteoporosis of the lumbar spine, six the criteria for osteopenia; at the total hip level, two met the criteria for osteoporosis and ten had osteopenia. Although there were only four males included in the PWS group, we found significantly lower $\mathrm{T}$-scores of the lumbar spine and hip in men when compared to women. As expected, we found a significant higher height, weight, WHR and FFM in the males than in the females of the control group. In the PWS group these sex differences were not seen, however as mentioned before there were only four males included. We were not able to analyze differences between genetic subtypes since fourteen PWS patients had a paternal deletion and only one subject a maternal uniparental disomy.

In Table 2 (panel A), markers of metabolic status, bone remodeling markers and appetite regulating factors in PWS patients are displayed, as well as IGF-1 levels in PWS patients (panel A) and healthy controls (panel B). There were no significant differences between male and female PWS adults. One patient had an HbA1c level which was elevated and treatment for diabetes mellitus was started. Only three PWS patients had a hs-CRP concentration $<$ $3 \mathrm{mg} / \mathrm{L}$. Adiponectin levels were within reference values in all subjects. Three of the four male and nine of the eleven female PWS subjects had leptin levels above reference values. Resistin levels were below the reference value in seven of the fifteen PWS subjects and normal in the remaining subjects. IGF-1 concentration and IGF-1 SDS were significantly lower in PWS subjects when compared to healthy controls. Although mostly within normal range, osteocalcin levels were low in PWS patients.

In Table 3, correlation coefficients are shown between measurements of body composition, IGF-1, appetite regulating peptides and measurements of glucose homeostasis within the total group of PWS patients. Measurements of body composition as measured by BIA correlated significantly with those measured by DXA (data not shown), we therefore only display the correlation coefficients for FM and lean body mass (LBM) as measured by DXA for a better overview. We found a significant correlation between IGF-1 concentration and age $(\mathrm{r}-0.54, \mathrm{p}$ 0.04) and IGF-1 concentration and IGFBP-3 ( $\mathrm{r}$ 0.70, p 0.004) in the total PWS group (data not shown). There were no significant correlations between IGF-1, IGFBP-3 or IGF-1/IGFBP-3 ratio and measurements of body composition, HOMA or adipokines. There was a significant positive correlation between BMI and FM, LBM, HOMA index, leptin, resistin and hs-CRP. Also, there was a significant negative correlation between HbA1c and adiponectin and between HOMA index and ghrelin. Leptin had a significant positive correlation with BMI, FM, LBM, glucose, insulin, HOMA index and hs-CRP. Furthermore, there was a significant negative correlation between adiponectin and resistin. There was no significant correlation between age and appetite regulating peptides. We also investigated whether there were significant correlations between IGF-1 and measurements of BMC, BMD and markers of bone metabolism. We found a significant correlation between IGF-1 SDS and alkaline phosphatase $(\mathrm{r}-0.624, p<0.05)$. Correlations between IGF-1 concentration and alkaline phosphatase and between IGF-1 SDS and BMC of the lumbar spine were nearly significant. There was a positive, but non-significant, correlation between osteocalcin and IGF-1, IGFBP-3 and IGF1/IGFBP-3 ratio (data not shown). Because of a lack of power, we were not able to investigate differences in correlation coefficients between male and female subjects or between genetic subtypes within the PWS group.

\section{Discussion}

In this study we investigated body composition, bone mineral density, markers of bone remodeling, appetite regulating peptides and IGF-1 levels in a group of PWS adults. As expected, there was a significant difference in body composition between PWS subjects and healthy controls, with a higher fat mass and lower lean body mass in PWS patients. It must be noted that our study 
Table 1 Body composition characteristics and measurements of bone mineral density in PWS patients and control group

\begin{tabular}{|c|c|c|c|c|c|c|c|c|c|c|c|c|}
\hline & \multicolumn{6}{|l|}{ PWS } & \multicolumn{6}{|l|}{ Controls } \\
\hline & \multicolumn{2}{|l|}{ Total group } & \multicolumn{2}{|l|}{ Men } & \multicolumn{2}{|l|}{ Women } & \multicolumn{2}{|l|}{ Total group } & \multicolumn{2}{|l|}{ Men } & \multicolumn{2}{|l|}{ Women } \\
\hline & $(N=15)$ & IQR & $(N=4)$ & IQR & $(N=11)$ & IQR & $(N=14)$ & IQR & $(N=7)$ & IQR & $(N=7)$ & IQR \\
\hline Age, years & 22.0 & 12.9 & 26.6 & 18.3 & 20.9 & 12.9 & 28.5 & 18.0 & 28.4 & 17.4 & 28.7 & 20.1 \\
\hline \multicolumn{13}{|l|}{ Sex } \\
\hline Female, \% & 73.3 & & & & & & 50.0 & & & & & \\
\hline Male, \% & 26.7 & & & & & & 50.0 & & & & & \\
\hline \multicolumn{13}{|l|}{ Genetic subtype } \\
\hline Deletion, \% & 93.3 & & & & & & & & & & & \\
\hline UPD, \% & 6.7 & & & & & & & & & & & \\
\hline Height, m & $1.58^{* *}$ & 0.08 & 1.60 & 0.09 & 1.57 & 0.10 & 1.77 & 0.17 & $1.86 \# \#$ & 0.066 & 1.69 & 0.048 \\
\hline Weight, kg & 69.5 & 33.6 & 67.9 & 32.9 & 70.3 & 37.1 & 73.1 & 15.9 & 79.1\# & 15.9 & 65.2 & 14.1 \\
\hline $\mathrm{BMl}, \mathrm{kg} / \mathrm{m}^{2}$ & $27.5^{*}$ & 16.7 & 26.1 & 13.2 & 32.1 & 20.3 & 22.4 & 4.6 & 22.7 & 5.1 & 22.0 & 5.8 \\
\hline Waist, $\mathrm{cm}$ & $94.8^{*}$ & 27.5 & 94.3 & 17.1 & 94.8 & 43.8 & 80.2 & 19.3 & 84.5 & 11.4 & 71.2 & 24.2 \\
\hline Hip, cm & 107 & 33.3 & 102.5 & 21.1 & 120.2 & 34.2 & 98.9 & 8.0 & 102.1 & 5.4 & 97.8 & 15.3 \\
\hline WHR & $0.87^{*}$ & 0.13 & 0.93 & 0.12 & 0.87 & 0.10 & 0.82 & 0.14 & $0.84 \#$ & 0.07 & 0.73 & 0.10 \\
\hline $\mathrm{FM}, \mathrm{kg}(\mathrm{BIA})$ & $28.5^{* *}$ & 23.5 & 25.4 & 21.6 & 30.1 & 23.5 & 14.2 & 9.9 & 13.8 & 2.9 & 14.5 & 10.0 \\
\hline FFM, kg (BIA) & $44.2^{* *}$ & 16.2 & 44.2 & 16.1 & 44.2 & 16.2 & 56.2 & 18.0 & $66.2 \#$ & 13.6 & 48.5 & 5.7 \\
\hline $\mathrm{FM}, \%(\mathrm{~B} \mid \mathrm{A})$ & $42.4^{* *}$ & 12.4 & 37.5 & 12.3 & 42.4 & 11.1 & 20.6 & 12.3 & 16.7 & 4.8 & 25.1 & 12.1 \\
\hline FFM, \% (BIA) & $57.6^{* *}$ & 12.4 & 62.5 & 12.4 & 57.6 & 11.1 & 79.4 & 12.3 & 83.3 & 4.8 & 74.9 & 12.1 \\
\hline $\mathrm{BMC}, \%(\mathrm{BI})$ & $30.0^{* *}$ & 11.4 & 32.5 & 8.1 & 29.7 & 12.2 & 42.8 & 9.7 & 44.5 & 7.3 & 40.3 & 22.1 \\
\hline BMC Lumbar spine, g (DXA) & 41.0 & 13.8 & 41.7 & 17.0 & 41.0 & 11.4 & & & & & & \\
\hline BMD Lumbar spine, $\mathrm{g} / \mathrm{cm}^{2}$ (DXA) & 0.91 & 0.17 & 0.80 & 0.28 & 0.93 & 0.20 & & & & & & \\
\hline T-score Lumbar spine, SDS (DXA) & -1.4 & 2.0 & $-2.6 \#$ & 2.5 & -0.9 & 1.5 & & & & & & \\
\hline Z-score Lumbar spine, SDS (DXA) & -1.7 & 1.4 & -2.6 & 2.4 & -1.0 & 1.7 & & & & & & \\
\hline BMC Total hip, g (DXA) & 23.0 & 5.1 & 22.9 & 3.5 & 23.0 & 8.4 & & & & & & \\
\hline BMD Total hip, g/cm² (DXA) & 0.76 & 0.10 & 0.74 & 0.13 & 0.76 & 0.15 & & & & & & \\
\hline T-score Total hip, SDS (DXA) & -1.6 & 0.9 & $-2.0 \#$ & 0.9 & -1.2 & 1.5 & & & & & & \\
\hline Z-score Total hip, SDS (DXA) & -1.5 & 1.1 & -2.0 & 0.8 & -1.4 & 1.3 & & & & & & \\
\hline Total BMC, g (DXA) & 1763 & 386 & 1684 & 368 & 1763 & 423 & & & & & & \\
\hline Total BMD, g/cm² (DXA) & 0.99 & 0.13 & 0.95 & 0.14 & 0.99 & 0.14 & & & & & & \\
\hline $\mathrm{FM}, \mathrm{kg}(\mathrm{DXA})$ & 33.5 & 19.4 & 28.5 & 17.1 & 39.5 & 26.5 & & & & & & \\
\hline LBM, kg (DXA) & 40.5 & 13.0 & 41.3 & 13.1 & 40.5 & 15.3 & & & & & & \\
\hline $\mathrm{FM}, \%$ (DXA) & 45.1 & 11.4 & 40.4 & 9.3 & 47.8 & 12.5 & & & & & & \\
\hline
\end{tabular}

$B M I$ body mass index, WHR waist-to-hip ratio, FM fat mass, FFM fat free mass, $B M C$ bone mineral content, $B M D$ bone mineral density, $L B M$ lean body mass All data are presented as median with interquartile range (IQR)

* Significant difference when compared to control group, $p<0.05 ; * * 0.01$

\# Significant difference when compared to other sex within group, $p<0.05$; \#\# $p<0.01$

group of PWS patients, with a median BMI of $27.5 \mathrm{~kg}$ / $\mathrm{m}^{2}$, was only mildly obese when compared to previously studied PWS adults. IGF-1 levels were decreased in PWS subjects when compared to healthy controls. Since there was no significant correlation between BMI and both IGF-1 concentration and IGF-1 SDS, this reduced level of IGF-1 is not solely explained by obesity. We found no significant correlations between IGF-1, IGFBP3 or IGF-1/IGFBP-3 ratio and measurements of body composition, HOMA or adipokines. In an earlier study we have already described the presence of growth hormone deficiency in a part of our study population [39]. $\mathrm{GH}$ treatment within three months prior to the study period was an exclusion criterion, but four of the PWS patients were treated with $\mathrm{GH}$ in the past as mentioned before. This might have influenced our results since growth hormone has effects on body composition, insulin sensitivity, adipokines and bone mineral density. 
Table 2 IGF-1 levels, markers of metabolic status, bone remodeling markers and appetite regulating factors in PWS patients (panel A) and IGF-1 levels in healthy controls (panel B)

\begin{tabular}{|c|c|c|c|c|c|c|}
\hline \multirow[t]{3}{*}{ Panel A } & \multicolumn{6}{|l|}{ PWS } \\
\hline & \multicolumn{2}{|l|}{ Total group } & \multicolumn{2}{|l|}{ Men } & \multicolumn{2}{|l|}{ Women } \\
\hline & $(N=15)$ & IQR & $(N=4)$ & IQR & $(N=11)$ & IQR \\
\hline $\mid G F-1, \mathrm{nmol} / \mathrm{L}$ & 14.6 & 7.7 & 16.0 & 11.9 & 14.6 & 7.7 \\
\hline IGF-1, SDS & -1.94 & 1.24 & -1.55 & 1.24 & -1.96 & 1.00 \\
\hline IGFBP-3, mg/L & 4.30 & 1.38 & 4.73 & 2.87 & 4.02 & 1.89 \\
\hline Calcium, mmol/L & 2.42 & 0.17 & 2.43 & 0.30 & 2.42 & 0.09 \\
\hline Albumin, g/L & 43.0 & 5.0 & 42.5 & 12.0 & 43.0 & 4.0 \\
\hline Creatinine, $\mu \mathrm{mol} / \mathrm{L}$ & 69.0 & 10.0 & 71.0 & 28.0 & 69.0 & 10.0 \\
\hline Alkaline phosphatase, U/L & 103.0 & 54.0 & 98.0 & 57.0 & 106.0 & 61.0 \\
\hline Phosphate, mmol/L & 1.12 & 0.31 & 0.91 & 0.47 & 1.16 & 0.26 \\
\hline 25(OH)D, nmol/L & 61.0 & 34.0 & 83.5 & 66.0 & 54.0 & 31.0 \\
\hline Osteocalcin, nmol/L & 0.90 & 2.49 & 0.77 & 2.28 & 1.24 & 2.49 \\
\hline Total cholesterol, mmol/L & 4.8 & 1.8 & 4.9 & 2.6 & 4.8 & 1.8 \\
\hline $\mathrm{HDL}, \mathrm{mmol} / \mathrm{L}$ & 1.3 & 0.5 & 1.2 & 0.7 & 1.3 & 0.4 \\
\hline $\mathrm{LDL}, \mathrm{mmol} / \mathrm{L}$ & 2.9 & 1.2 & 2.1 & NA & 3.2 & 1.0 \\
\hline Triglycerides, mmol/L & 0.80 & 0.30 & 1.75 & 2.60 & 0.80 & 0.30 \\
\hline Glucose, mmol/L & 4.2 & 1.0 & 4.2 & 0.2 & 4.0 & 1.3 \\
\hline $\mathrm{HbA1c}, \%$ & 5.4 & 0.4 & 5.6 & 3.1 & 5.4 & 0.4 \\
\hline Insulin, pmol/L & 30.6 & 36.8 & 37.2 & 179.1 & 29.1 & 38.5 \\
\hline HOMA index & 0.58 & 0.62 & 0.66 & 3.04 & 0.55 & 0.64 \\
\hline Leptin, $\mu g / L$ & 21.5 & 33.2 & 20.1 & 38.7 & 24.9 & 33.2 \\
\hline Ghrelin, ng/L & 2476 & 2080 & 2118 & 2201 & 2612 & 2092 \\
\hline Resistin, ng/ml & 4.4 & 3.6 & 4.3 & 5.7 & 4.4 & 3.6 \\
\hline Adiponectin, mg/L & 13.9 & 6.7 & 13.2 & 9.1 & 13.9 & 6.4 \\
\hline $\mathrm{Hs}-\mathrm{CRP}, \mathrm{mg} / \mathrm{L}$ & 4.04 & 10.39 & 3.48 & 8.01 & 7.54 & 19.68 \\
\hline Urine Calcium, mmol/24 h & 0.20 & 0.5 & 0.55 & 1.1 & 0.20 & 0.2 \\
\hline Urine Creatitine, mmol/24 h & 1.74 & 1.47 & 3.27 & 2.86 & 1.70 & 0.69 \\
\hline Urine Hydroxyprolin, mmol/24 h & 0.046 & 0.028 & 0.055 & 0.087 & 0.046 & 0.027 \\
\hline Urine Hydroxyprolin/Creatinin ratio & 25.2 & 21.2 & 23.2 & 40.9 & 25.2 & 20.4 \\
\hline \multirow[t]{3}{*}{ Panel B } & \multicolumn{6}{|l|}{ Controls } \\
\hline & \multicolumn{2}{|l|}{ Total group } & \multicolumn{2}{|l|}{ Men } & \multicolumn{2}{|l|}{ Women } \\
\hline & $(N=14)$ & IQR & $(N=7)$ & IQR & $(N=7)$ & IQR \\
\hline$|G F-1, n m o| / L$ & 21.8 & 11.6 & 21.4 & 14.2 & 22.1 & 10.5 \\
\hline IGF-1, SDS & -0.79 & 1.06 & -1.00 & 1.07 & -0.76 & 1.72 \\
\hline
\end{tabular}

All data are presented as median with interquartile range (IQR)

Also, hypogonadal state might have influenced body composition measurements in our patient group, since $46 \%$ of the PWS patients with hypogonadism were not treated with sex hormones.

In agreement with other studies, leptin and hs-CRP concentrations were elevated in the majority of our PWS patients and adiponectin levels were within the reference range in all patients [23, 25-27, 34-36, 41, 42]. Resistin levels were normal or decreased, which is in contrast to earlier reported data in PWS patients and to studies in simple obesity, where resistin levels are known to be elevated [26]. There was a significant positive correlation between BMI and leptin, resistin, HOMA-IR and hs-CRP, and also between HOMA index and leptin and ghrelin. Many of the correlations we found are consistent with earlier published results in PWS patients and subjects with simple obesity.

BMD is reported to be decreased and markers of bone turnover elevated in PWS subjects [23, 37, 38]. In 
Table 3 Correlation coefficients of measurements of body composition, IGF-1, appetite regulating peptides and measurements of glucose homeostasis within the PWS patients (total group)

\begin{tabular}{|c|c|c|c|c|c|c|c|c|c|c|c|c|c|}
\hline & BMI & FM & LBM & IGF-1 & Glucose & $\mathrm{HbA1c}$ & Insulin & HOMA & Leptin & Ghrelin & Resistin & Adiponectin & $\mathrm{Hs}-\mathrm{CRP}$ \\
\hline BMI $\left(\mathrm{kg} / \mathrm{m}^{2}\right)$ & 1.00 & $0.96^{* *}$ & $0.75^{* *}$ & -0.18 & 0.19 & 0.16 & 0.44 & $0.55^{*}$ & $0.83^{* *}$ & -0.44 & $0.58^{*}$ & -0.31 & $0.77^{* *}$ \\
\hline FM (g, DXA) & $0.96^{* *}$ & 1.00 & $0.69^{* *}$ & -0.14 & 0.19 & 0.18 & 0.36 & 0.46 & $0.78^{* *}$ & -0.33 & $0.53^{*}$ & -0.30 & $0.88^{* *}$ \\
\hline LBM $(g, D X A)$ & $0.75^{* *}$ & $0.69^{* *}$ & 1.00 & 0.02 & 0.02 & 0.32 & 0.46 & 0.51 & $0.54^{*}$ & -0.46 & $0.69^{* *}$ & -0.44 & $0.66^{* *}$ \\
\hline IGF-1 (nmol/L) & -0.18 & -0.14 & 0.02 & 1.00 & -0.03 & -0.18 & 0.26 & 0.04 & -0.04 & -0.11 & 0.01 & -0.39 & -0.27 \\
\hline Glucose (mmol/L) & 0.19 & 0.19 & 0.02 & -0.03 & 1.00 & 0.14 & $0.67^{* *}$ & $0.65^{*}$ & $0.51^{*}$ & -0.34 & 0.20 & -0.45 & 0.39 \\
\hline HbA1c (\%) & 0.16 & 0.18 & 0.32 & -0.18 & 0.14 & 1.00 & 0.02 & 0.09 & 0.14 & 0.10 & 0.35 & $-0.58^{*}$ & 0.41 \\
\hline Insulin (pmol/L) & 0.44 & 0.36 & 0.46 & 0.26 & $0.67^{* *}$ & 0.02 & 1.00 & $0.99 * *$ & $0.69^{* *}$ & -0.48 & 0.39 & -0.46 & 0.33 \\
\hline HOMA (index) & $0.55^{*}$ & 0.46 & 0.51 & 0.04 & $0.65^{*}$ & 0.09 & $0.99^{* *}$ & 1.00 & $0.67^{* *}$ & $-0.58^{*}$ & $0.54^{*}$ & -0.34 & 0.41 \\
\hline Leptin $(\mu \mathrm{g} / \mathrm{L})$ & $0.83^{* *}$ & $0.78^{* *}$ & $0.54^{*}$ & -0.04 & $0.51^{*}$ & 0.14 & $0.69^{* *}$ & $0.67^{* *}$ & 1.00 & -0.41 & 0.37 & -0.39 & $0.66^{* *}$ \\
\hline Ghrelin (ng/L) & -0.44 & -0.33 & -0.46 & -0.11 & -0.34 & 0.10 & -0.48 & $-0.58^{*}$ & -0.41 & 1.00 & -0.31 & 0.29 & -0.24 \\
\hline Resistin (ng/ml) & $0.58^{*}$ & $0.53^{*}$ & $0.69^{* *}$ & 0.01 & 0.20 & 0.35 & 0.39 & $0.54^{*}$ & 0.37 & -0.31 & 1.00 & $-0.56^{*}$ & $0.51^{*}$ \\
\hline Adiponectin (mg/L) & -0.31 & -0.30 & -0.44 & -0.39 & -0.45 & $-0.58^{*}$ & -0.46 & -0.34 & -0.39 & 0.29 & $-0.56^{*}$ & 1.00 & -0.47 \\
\hline $\mathrm{Hs}-\mathrm{CRP}$ (mg/L) & $0.77^{* *}$ & $0.88^{* *}$ & $0.66^{* *}$ & -0.27 & 0.39 & 0.41 & 0.33 & 0.41 & $0.66^{* *}$ & -0.24 & $0.51^{*}$ & -0.47 & 1.00 \\
\hline
\end{tabular}

* Significant correlation, $p<0.05$; * $p<0.01$

accordance we found a high prevalence of osteopenia and osteoporosis in our PWS subjects, most pronounced in the male subjects. This was accompanied by low levels of osteocalcin, which is produced by osteoblast and used as a marker of bone formation. The abnormal body composition, low levels osteocalcin and higher prevalence of osteopenia and osteoporosis seen in PWS patients could, at least partially, be explained by endocrine disorders such as growth hormone deficiency and hypogonadism. Data on the GH/IGF-1 axis and BMD or bone metabolism in PWS adults are very scarce. We found a near significant positive correlation between IGF-1 SDS and BMC of the lumbar spine and a significant negative correlation between IGF-1 SDS and alkaline phosphatase. There was a positive, but nonsignificant, correlation between osteocalcin and IGF-1, IGFBP-3 and IGF-1/IGFBP-3 ratio. Concentrations of osteocalcin were low, which was more pronounced in men than in women, although not significantly. This may indicate a low level of bone formation. It is known that IGF-1 is an important stimulatory factor for bone formation. That we did not find a significant correlation between IGF-1 levels and osteocalcin in this study could be a result of the small number of patients included and the low levels of both IGF-1 and osteocalcin with a small spread within the PWS patients. Since there was a significant negative correlation between IGF-1 and alkaline phosphatase in our PWS patients, there may be a disturbance between bone formation and bone resorption in PWS patients, resulting in low BMD, which might be related to alterations in IGF1 levels. However, both IGF-1 levels and bone remodelling are known to be influenced by sex steroids. In PWS patients there is a high prevalence of hypogonadism [39, 43, 44]. In our total group of PWS subjects, there was a significant negative correlation between testosterone levels and BMD of the lumbar spine $(\mathrm{r}-0.674, \mathrm{p} 0.016)$ and $\mathrm{a}$ near significant positive correlation between estradiol concentration and BMD of the total hip ( $\mathrm{r}$ 0.509, p 0.052). These correlations were not significant when analysed for both sexes separately (data not shown), but as mentioned earlier those groups were small. It is possible that the low BMD we found in our study is caused by (a combination of) low IGF-1 levels as well as a hypogonadal state. Furthermore, a lower level of physical activity with less weight-bearing stress on the bones could also attribute to a lower BMD in PWS patients [5]. Median 25-hydroxyvitamin D level was $61 \mathrm{nmol} / \mathrm{L}$ in our PWS study population, therefore vitamin D deficiency as a cause of low BMD is unlikely. We are not informed about fractures in our study population, therefore we could not investigate whether there is a relation between IGF-1 levels, BMD and fracture risk.

There are some limitations to our study. We included a relatively small number of patients and we performed several statistical tests on the study data. Therefore it is difficult to draw hard conclusions from our study results. However, since PWS has a low prevalence, it is very difficult to perform a study like ours in large patient groups. We tested for differences between both sexes and the results indicate that there is a difference for some of the investigated variables, but since there were only four male PWS subjects included, the results should be interpreted with caution. Sex differences in correlation coefficients and differences between genetic subtypes of PWS could not be analyzed. Unfortunately no measurements of appetite regulating hormones and DXA have been performed in the healthy controls. Therefore, it was not possible to investigate correlations between these different parameters in the 
control subjects or compare the results found in PWS patients to the control group.

Life expectancy in individuals with Prader-Willi syndrome is decreased and this shortened lifespan is mainly the result of metabolic, cardiovascular and respiratory complications. There might be a difference in causes of death between gender and genetic subtype of PWS [45]. Our results indicate that there is a relation between an increased BMI and a higher level of insulin resistance and low-grade systemic inflammation which is likely to attribute to the high percentage of metabolic and cardiovascular morbidity and mortality that has been described in PWS adults. There is no cure for PWS and therefore treatment should be aimed at preventing the complications seen in PWS. Many of the clinical features described in PWS patients are comparable to those seen in patients with GHD. Studies with growth hormone replacement therapy (GHT), performed mostly in children with PWS but also in adult PWS subjects, show positive effects on height, FM, LBM, visceral adipose tissue, HDL-cholesterol, CRP, adiponectin, physical activity, cardiovascular features, cognition and quality of life without significant impairments in glucose homeostasis [30, 4655]. Whether the positive effects of GHT differ for PWS patients with and without affirmed GHD is not known.

Further investigations in larger groups of PWS patients are warranted to gain more insight into the exact pathophysiology of the aberrant body composition, appetite regulating hormones, decreased BMD and the metabolic and cardiovascular complications seen in PWS. It is not known whether screening for metabolic and cardiovascular diseases and early preventive treatment with, for instance, statins has a positive effect on morbidity and survival in PWS patients. Also, there are no data on the effects of treatment with calcium and vitamin $\mathrm{D}$ or bisphosphonates on BMD and fracture risk. Because of the promising effects of GH therapy thus far, more studies on the long term effects of GHT not only in children with PWS but also in adults are desirable. Furthermore, it is interesting to study whether the effects of GHT are seen in all PWS patients or only in those with affirmed GHD. Whether the hyperphagia and obesity seen in PWS is a result of decreased satiation or increased hunger is still unclear. Therefore, the exact role of appetite regulating factors in individuals with PWS warrants further investigation especially in larger cohorts with older PWS patients. It would be interesting to study changes in body composition and adipokines in course of time, for example before and after weight loss.

Nowadays, there is more awareness of the diagnosis PWS and genetic tests for PWS are more accessible. Thereby, the diagnosis PWS is made at younger age and preventive measures for obesity and treatment with $\mathrm{GH}$ can be started early in life. Life expectancy of subjects with Prader-Willi syndrome has increased in recent years and the average BMI, like in our study population, is already lower than reported before. Preventive measures and early treatment can contribute to longer survival, a decrease in morbidity, and possibly a better quality of life and lower healthcare costs.

\section{Conclusion}

In adults with Prader-Willi syndrome alterations in body composition, adipokines, hs-CRP and bone mineral density were demonstrated but these were not associated with IGF-1 levels. Further investigations are warranted to gain more insight into the exact pathophysiology and the role of these alterations in the metabolic and cardiovascular complications seen in PWS. Since there is no cure for PWS and patients with PWS live longer nowadays, prevention and treatment of these complications as early as possible is of great importance.

\section{Abbreviations}

BC: Body composition; BIA: Bioelectric impedance analysis; BMC: Bone mineral content; BMD: Bone mineral density; BMI: Body mass index; DXA: Dual-energy X-ray absorptiometry; FFM: Fat free mass; GH: Growth hormone; GHD: Growth hormone deficiency; GHT: Growth hormone replacement therapy; HOMA-IR: Homeostasis model assessment of insulin resistance; hs-CRP: High-sensitive C-reactive protein; IGF-1: Insulin-like growth factor-1; IGFBP-3: Insulin-like growth factor binding protein-3; LBM: Lean body mass; OGTT: Oral glucose tolerance test; PWS: Prader-Willi syndrome; SDS: Standard deviation scores; WHR: Waist-to-hip ratio

\section{Acknowledgements}

We are very grateful to all PWS patients, their parents/caretakers and brothers/sisters for their participation in this study. Furthermore we are thankful to the Dutch Prader-Willi Patients'Association for their help in recruiting PWS patients for this study. We would also like to thank dr. A. Heijboer and all technicians from the endocrine laboratory of the VU University Medical Center for their support.

\section{Funding}

This study was partly funded by an independent grant from Pfizer Inc., The Netherlands.

\section{Availability of data and materials}

The data is available from the corresponding author on reasonable request.

\section{Authors' contributions}

ICVN participated in the study design, data collection and entry, statistical analysis and interpretation of data and writing of final manuscript. JWRT participated in the study design, statistical analysis and completion of final manuscript. LMGC participated in the study design and completion of final manuscript. PL participated in the study design and completion of final manuscript. MLD participated in the study design, data collection, statistical analysis and interpretation of data, supervision and completion of final manuscript. All authors read and approved the final manuscript.

\section{Ethics approval and consent to participate}

This study was a cross-sectional observational study which was approved by the Medical Ethics Review Committee of the VU University Medical Center and was conducted according to the principles of the Helsinki Declaration.

Consent for publication

Not applicable.

Competing interests

The authors declare that they have no competing interests. 


\section{Publisher's Note}

Springer Nature remains neutral with regard to jurisdictional claims in published maps and institutional affiliations.

\section{Author details}

'Department of Internal Medicine, Section Endocrinology, VU University Medical Center and Amsterdam Neuroscience, De Boelelaan 1117, 1081 HV Amsterdam, The Netherlands. ${ }^{2}$ Department of Clinical Epidemiology and Biostatistics and EMGO Institute, VU University Medical Center and Institute of Health Sciences, VU University, Amsterdam, The Netherlands. ${ }^{3}$ Department of Clinical Genetics, Maastricht University Medical Center, Maastricht, The Netherlands.

Received: 19 July 2017 Accepted: 10 January 2018

Published online: 16 January 2018

\section{References}

1. Cassidy SB, Driscoll DJ. Prader-Willi syndrome. Eur J Hum Genet. 2009;17(1):3-13.

2. Holm VA, et al. Prader-Willi syndrome: consensus diagnostic criteria. Pediatrics. 1993:91(2):398-402.

3. Prader A, Labhart A, Willi H. Ein Syndrom von Adipositas, Kleinwuchs, Kryptorchismus und Oligophrenie nach myatonieartigem Zustand im Neugeborenenalter. Schweiz Med Wochenschr. 1956;86:1260-1.

4. Swaab DF. Prader-Willi syndrome and the hypothalamus. Acta Paediatr Suppl. 1997:423:50-4.

5. Khan MJ, et al. Mechanisms of obesity in Prader-Willi syndrome. Pediatr Obes. 2018;13(1):3-13

6. Brambilla P, et al. Peculiar body composition in patients with PraderLabhart-Willi syndrome. Am J Clin Nutr. 1997;65(5):1369-74.

7. Butler MG, et al. Energy expenditure and physical activity in Prader-Willi syndrome: comparison with obese subjects. Am J Med Genet A. 2007; 143(5):449-59.

8. Davies PS. Body composition in Prader-Willi syndrome: assessment and effects of growth hormone administration. Acta Paediatr Suppl. 1999; 88(433):105-8.

9. Goldstone AP, et al. Visceral adipose tissue and metabolic complications of obesity are reduced in Prader-Willi syndrome female adults: evidence for novel influences on body fat distribution. J Clin Endocrinol Metab. 2001; 86(9):4330-8.

10. Hoybye $C$, et al. Metabolic profile and body composition in adults with PraderWilli syndrome and severe obesity. J Clin Endocrinol Metab. 2002;87(8):3590-7.

11. Kennedy L, et al. Circulating adiponectin levels, body composition and obesity-related variables in Prader-Willi syndrome: comparison with obese subjects. Int J Obes. 2006;30(2):382-7.

12. Sode-Carlsen $\mathrm{R}$, et al. Body composition, endocrine and metabolic profiles in adults with Prader-Willi syndrome. Growth Hormon IGF Res. 2010;20(3):179-84

13. Sobrino CC, et al. Peptides and food intake. Front Endocrinol (Lausanne). 2014:5:58.

14. Cummings DE, et al. Elevated plasma ghrelin levels in Prader Will syndrome. Nat Med. 2002;8(7):643-4.

15. Feigerlova $\mathrm{E}$, et al. Hyperghrelinemia precedes obesity in Prader-Willi syndrome. J Clin Endocrinol Metab. 2008;93(7):2800-5.

16. Goldstone AP, et al. Elevated fasting plasma ghrelin in prader-willi syndrome adults is not solely explained by their reduced visceral adiposity and insulin resistance. J Clin Endocrinol Metab. 2004;89(4):1718-26.

17. Haqq AM, et al. Serum ghrelin levels are inversely correlated with body mass index, age, and insulin concentrations in normal children and are markedly increased in Prader-Willi syndrome. J Clin Endocrinol Metab. 2003;88(1):174-8.

18. Paik $\mathrm{KH}$, et al. Correlation between fasting plasma ghrelin levels and age, body mass index (BMI), BMI percentiles, and 24-hour plasma ghrelin profiles in Prader-Willi syndrome. J Clin Endocrinol Metab. 2004;89(8):3885-9.

19. DelParigi $A$, et al. High circulating ghrelin: a potential cause for hyperphagia and obesity in prader-willi syndrome. J Clin Endocrinol Metab. 2002;87(12):5461-4.

20. Kweh FA, et al. Hyperghrelinemia in Prader-Willi syndrome begins in early infancy long before the onset of hyperphagia. Am J Med Genet A. 2015;167A(1):69-79.

21. Piya MK, McTernan PG, Kumar S. Adipokine inflammation and insulin resistance: the role of glucose, lipids and endotoxin. J Endocrinol. 2013; 216(1):T1-T15.
22. Goldstone AP, et al. Resting metabolic rate, plasma leptin concentrations, leptin receptor expression, and adipose tissue measured by whole-body magnetic resonance imaging in women with Prader-Willi syndrome. Am J Clin Nutr. 2002;75(3):468-75.

23. Hoybye C. Endocrine and metabolic aspects of adult Prader-Willi syndrome with special emphasis on the effect of growth hormone treatment. Growth Hormon IGF Res. 2004;14(1):1-15.

24. Proto $C_{\text {, et }}$ al. Free and total leptin serum levels and soluble leptin receptors levels in two models of genetic obesity: the Prader-Willi and the down syndromes. Metabolism. 2007;56(8):1076-80.

25. Eiholzer U, Blum WF, Molinari L. Body fat determined by skinfold measurements is elevated despite underweight in infants with PraderLabhart-Willi syndrome. J Pediatr. 1999:134(2):222-5.

26. Pagano $C$, et al. Increased serum resistin in adults with prader-willi syndrome is related to obesity and not to insulin resistance. J Clin Endocrinol Metab. 2005;90(7):4335-40.

27. Butler MG, et al. Comparison of leptin protein levels in Prader-Willi syndrome and control individuals. Am J Med Genet. 1998;75(1):7-12.

28. Caixas $A$, et al. Postprandial adiponectin levels are unlikely to contribute to the pathogenesis of obesity in Prader-Willi syndrome. Horm Res. 2006;65(1):39-45.

29. Hoybye $C$, et al. Serum adiponectin levels in adults with Prader-Willi syndrome are independent of anthropometrical parameters and do not change with GH treatment. Eur J Endocrinol. 2004;151(4):457-61.

30. Mogul HR, et al. Growth hormone treatment of adults with Prader-Willi syndrome and growth hormone deficiency improves lean body mass, fractional body fat, and serum triiodothyronine without glucose impairment: results from the United States multicenter trial. J Clin Endocrinol Metab. 2008:93(4):1238-45.

31. Talebizadeh Z, Butler MG. Insulin resistance and obesity-related factors in Prader-Willi syndrome: comparison with obese subjects. Clin Genet. 2005; 67(3):230-9

32. Zipf WB. Glucose homeostasis in Prader-Willi syndrome and potential implications of growth hormone therapy. Acta Paediatr Suppl. 1999;88(433):115-7.

33. Cadoudal T, et al. Impairment of adipose tissue in Prader-Willi syndrome rescued by growth hormone treatment. Int J Obes (Lond). 2014;38(9):1234-40.

34. Butler MG, et al. C-reactive protein levels in subjects with Prader-Willi syndrome and obesity. Genet Med. 2006;8(4):243-8.

35. Caixas A, et al. Adult subjects with Prader-Willi syndrome show more lowgrade systemic inflammation than matched obese subjects. J Endocrinol Investig. 2008;31(2):169-75.

36. Hoybye C. Inflammatory markers in adults with Prader-Willi syndrome before and during 12 months growth hormone treatment. Horm Res. 2006;66(1):27-32.

37. Butler MG, et al. Decreased bone mineral density in Prader-Willi syndrome: comparison with obese subjects. Am J Med Genet. 2001;103(3):216-22.

38. Vestergaard $P$, et al. Reduced bone mineral density and increased bone turnover in Prader-Willi syndrome compared with controls matched for sex and body mass index-a cross-sectional study. J Pediatr. 2004;144(5):614-9.

39. van Nieuwpoort IC, et al. The GH/IGF-I Axis and Pituitary Function and Size in Adults with Prader-Willi Syndrome. Horm Res Paediatr. 2011;75(6):403-11.

40. Lukaski HC, et al. Assessment of fat-free mass using bioelectrical impedance measurements of the human body. Am J Clin Nutr. 1985:41(4):810-7.

41. Goldstone AP, et al. Appetite hormones and the transition to hyperphagia in children with Prader-Willi syndrome. Int J Obes. 2012;36(12):1564-70.

42. Viardot $A$, et al. Prader-Willi syndrome is associated with activation of the innate immune system independently of central adiposity and insulin resistance. J Clin Endocrinol Metab. 2010;95(7):3392-9.

43. Angulo MA, Butler MG, Cataletto ME. Prader-Willi syndrome: a review of clinical, genetic, and endocrine findings. J Endocrinol Invest. 2015;38(12):1249-63.

44. Hirsch HJ, et al. Sexual dichotomy of gonadal function in Prader-Willi syndrome from early infancy through the fourth decade. Hum Reprod. 2015;30(11):2587-96

45. Butler MG, et al. Causes of death in Prader-Willi syndrome: Prader-Willi Syndrome Association (USA) 40-year mortality survey. Genet Med. 2017;19(6):635-42.

46. Bakker NE, et al. Eight years of growth hormone treatment in children with Prader-Willi syndrome: maintaining the positive effects. J Clin Endocrinol Metab. 2013:98(10):4013-22.

47. Butler MG, et al. Effects of growth hormone treatment in adults with PraderWilli syndrome. Growth Hormon IGF Res. 2013:23(3):81-7.

48. Festen DA, et al. Randomized controlled GH trial: effects on anthropometry, body composition and body proportions in a large group of children with Prader-Willi syndrome. Clin Endocrinol. 2008;69(3):443-51. 
49. Festen DA, et al. Adiponectin levels in prepubertal children with Prader-Willi syndrome before and during growth hormone therapy. J Clin Endocrinol Metab. 2007;92(4):1549-54.

50. Grugni G, Sartorio A, Crino A. Growth hormone therapy for Prader-willi syndrome: challenges and solutions. Ther Clin Risk Manag. 2016;12:873-81.

51. Hazem A, et al. Body composition and quality of life in adults treated with GH therapy: a systematic review and meta-analysis. Eur J Endocrinol. 2012; 166(1):13-20.

52. Kuppens RJ, et al. Metabolic health profile in young adults with Prader-Willi syndrome: results of a 2-year randomized, placebo-controlled, crossover GH trial. Clin Endocrinol. 2017;86(2):297-304.

53. Sanchez-Ortiga R, Klibanski A, Tritos NA. Effects of recombinant human growth hormone therapy in adults with Prader-Willi syndrome: a metaanalysis. Clin Endocrinol. 2012;77(1):86-93.

54. Siemensma EP, et al. Beneficial effects of growth hormone treatment on cognition in children with Prader-Willi syndrome: a randomized controlled trial and longitudinal study. J Clin Endocrinol Metab. 2012;97(7):2307-14.

55. Sode-Carlsen R, et al. Growth hormone treatment in adults with Prader-Willi syndrome: the Scandinavian study. Endocrine. 2012;41(2):191-9.

\section{Submit your next manuscript to BioMed Central} and we will help you at every step:

- We accept pre-submission inquiries

- Our selector tool helps you to find the most relevant journal

- We provide round the clock customer support

- Convenient online submission

- Thorough peer review

- Inclusion in PubMed and all major indexing services

- Maximum visibility for your research

Submit your manuscript at www.biomedcentral.com/submit 